\title{
Inter-rater Reliability
}

National Cancer Institute

\section{Source}

National Cancer Institute. Inter-rater Reliability. NCI Thesaurus. Code C78688.

The extent to which two different researchers obtain the same result when using the same instrument to measure a concept. 